Pesq. Vet. Bras. 35(2):199-207, fevereiro 2015 DOI: $10.1590 / \mathrm{S} 0100-736 \mathrm{X} 2015000200018$

\title{
Morfologia das glândulas salivares de Glironia venusta Thomas, 1912 (Didelphimorphia) ${ }^{1}$
}

\author{
Bruna S. Vieira ${ }^{2 *}$, Cristiano O. Schuingues ${ }^{2}$, Mendelson G. de Lima ${ }^{3}$, \\ Daniele S. Martins ${ }^{4}$ e Gerlane M. Costa ${ }^{3}$
}

\begin{abstract}
Vieira B.S., Schuingues C.O., Lima M.G., Martins D.S. \& Costa G.M. 2015. [Morphology of salivary glands of the Glironia venusta Thomas, 1912 (Didelphimorphia).] Morfologia das glândulas salivares de Glironia venusta Thomas, 1912 (Didelphimorphia). Pesquisa Veterinária Brasileira 35(2):199-207. Universidade do Estado de Mato Grosso, Campus I, Rodovia MT-208 Km 147, Jardim Tropical, Alta Floresta, MT 78580-000, Brazil. E-mail: bruna_sakamotovieira@hotmail.com

The aim of this study was to describe the morphology of the salivary glands of Glironia venusta. A sample of $G$. venusta was collected in fauna rescue of hidroelectric usine of Teles Pires was used. This exemplar was fixed with formaldehyde solution $10 \%$. For macroscopic analysis, the glands were dissected and photographed in situ and for the microscopy fragments of the glands were removed, that were dehydrated in increasing alcohol concentrations, diaphanizated in xylene, included in paraffin and stained with hematoxylin and eosin. G. venusta presented the mandibular, parotid, sublingual, labial and zygomatic glands. The mandible is shown as elongated structures, composed of non-septated lobes and located in the anterior cervical region. With a triangular format, the parotid was located in the depression of the masseter, ventral an auricular cartilage. The sublingual were located ventral to the mandible, caudal to the digastric muscle. In the posterior dorsal portion, until the labial commissure, dorsal to the orbicularis muscle of mouth was observed the labial glands, which showed a " $U$ " shape. The zygomatic glands was accompanied the shape of the anterior portion of the zygomatic arch at the infraorbital margin. The mandibulars and sublinguals glands showed acini of mucous type, with some serous acini. The parotid one was made up purely by serous acini. In the labial gland was observed acini of mixed types mixed or seromucosous. Related the zygomatic gland was not possible to perform the microscopic analysis because of histological proceeding problems. Characteristics of the salivary glands observed in G. venusta resemble other omnivores mammals, but showed small differences as regards their location and shape.
\end{abstract}

INDEX TERMS: Salivary glands, Glironia venusta, Didelphimorphia, histology, digestory, marsupial.

RESUMO.- 0 objetivo deste trabalho foi descrever a morfologia das glândulas salivares de Glironia venusta. Foi utilizado um exemplar coletado no resgate de fauna da Usina

\footnotetext{
${ }^{1}$ Recebido em 21 de novembro de 2014.

Aceito para publicação em 25 de fevereiro de 2015.

${ }^{2}$ Graduados em Licenciatura Plena em Ciências Biológicas, Faculdade de Ciências Agrárias e Biológicas, Universidade do Estado de Mato Grosso (Unemat), Campus I, Rodovia MT-208 Km 147, Alta Floresta, MT 78580-000, Brasil.*Autor para correspondência: bruna_sakamotovieira@hotmail.com

${ }^{3}$ Departamento de Ciências Biológicas, Faculdade de Ciências Agrárias e Biológicas, Unemat, Campus I, Rodovia MT-208 Km 147, Alta Floresta, MT 8580-000. E-mails: mendelson@unemat.br, gerlanemcosta@yahoo.com.br

${ }^{4}$ Departamento de Medicina Veterinária, Faculdade de Zootecnia e Engenharia de Alimentos, Universidade de São Paulo (USP), Av. Duque de Caxias Norte 225, São Paulo, SP 13635-900, Brasil. E-mail: daniele@usp.br
}

Hidroeletrica Teles Pires. Este foi fixado com solução de formaldeído a 10\%. Para a análise macroscópica, as glândulas foram dissecadas e fotografadas in situ e para a microscopia foram retirados fragmentos das glândulas. Estes foram desidratados em concentrações crescentes de álcool, diafanizados em xilol, inclusos em parafina e corados com HE. $G$. venusta apresentou as glândulas mandibulares, parótidas, sublinguais, labiais e zigomáticas. As mandibulares se mostraram como estruturas alongadas, constituídas por lobos não septados e localizadas na porção anterior da região cervical. De formato triangular, a parótida estava localizada na depressão do masseter, ventral à cartilagem auricular. As sublinguais encontravam-se ventrais ao ramo da mandíbula, caudais ao digástrico. Foi observado na porção dor- 
soposterior à comissura labial, dorsal ao músculo orbicular da boca, as glândulas labiais, que apresentaram formato de "U". Já as glândulas zigomáticas acompanhavam a forma da porção anterior do arco zigomático, na margem infraorbital. As glândulas mandibulares e sublinguais apresentaram ácinos do tipo mucosos, com alguns ácinos serosos. A parótida era constituída por ácinos puramente serosos. Na glândula labial foi observado ácinos do tipo mistos ou seromucosos. Para a glândula zigomática não foi possível a realização da análise microscópica devido problemas de procedimento histológico. As características das glândulas salivares observadas em $G$. venusta se assemelham a de outros mamíferos onívoros, entretanto, apresentaram pequenas diferenças no que se refere à sua localização e forma.

TERMOS DE INDEXAÇÃO: Glândulas salivares, Glironia venusta, Didelphimorphia, histologia, digestório, marsupial.

\section{INTRODUÇÃO}

Glironia venusta, conhecido popularmente como cuíca, é um marsupial que pertence á ordem Didelphimorphia, com comprimento que varia de 160 a $205 \mathrm{~mm}$, orelhas grandes e ovais, coloração escura, com duas grandes faixas pretas sobre os olhos que dão a aparência de máscara e uma cauda longa recoberta de pêlos (Marshall 1978). A cauda é um recurso utilizado para distingui-lo dos outros gambás sul-americanos, sendo o único com a cauda recoberta de pêlos e comprimento maior que o de seu corpo, variando de 195205mm (Marshall 1978, Langguth \& Silva 1989, Emmons \& Feer 1990, Tarifa \& Anderson 1997). Habitam florestas tropicais amazônicas, localizadas no leste do Brasil, Bolívia, Peru e Equador (Langguth \& Silva 1989, Emmons \& Feer 1990, Tarifa \& Anderson 1997).

São considerados arbóreos e noturnos, porém pouco se sabe sobre seu comportamento (Marshall 1978, Emmons \& Feer 1990). Como a maioria dos mamíferos, eles provavelmente baseiam-se, principalmente, no olfato e audição, para encontrar alimento e evitar predadores (Marshall 1978). Fonseca et al. (1996) classificaram esta espécie como insetívora-onívora e outros autores sugerem que sua dieta inclui ovos, insetos, sementes e frutos (Emmons \& Feer 1997, Nowak 1999), com relatos de observações onde estes estavam se alimentando de exsudato (goma) de troncos de árvores

Todos os mamíferos precisam das secreções serosas e mucosas das glândulas salivares para lubrificar o alimento seco (George et al. 1998). 0 produto de secreção destas glândulas é a saliva que tem função de ação antibacteriana (Samuelson 2007), auxiliar na degustação e dissolução dos alimentos, colaborar no ajuste do $\mathrm{pH}$ do trato digestivo cranial, facilitar a mastigação, umedecer os alimentos e o epitélio da mucosa (George et al. 1998).

As glândulas salivares podem ser divididas em: maiores, compostas pelas glândulas parótidas, sublinguais e mandibulares, além da zigomática (carnívoros); e menores, que se situam na bochecha, lábios, palato, cavidade oral e mucosa da língua (Banks 1991, Vieira et al. 2001, Samuelson 2007, Santos et al. 2010b).

Não há estudos acerca da anatomia e histologia das glândulas salivares desta espécie, sendo assim, este trabalho teve como objetivo descrever a morfologia destas glândulas em Glironia venusta, com a finalidade de fornecer informações de biologia básica desta espécie.

\section{MATERIAL E MÉTODOS}

Foi utilizado um exemplar de Glironia venusta (número de tombo: MA0004), coletado no resgate de fauna da UHE Teles Pires, localizado nas coordenadas LONG 5646'35" W e LAT 0920'35" S, situada no Rio Teles Pires-MT. A pele foi rebatida da carcaça e taxidermizada. A carcaça foi fixada em solução de fomaldeído $10 \%$, a qual foi utilizada para dissecação e descrição das glândulas salivares.

Para a análise macroscópica, as glândulas foram dissecadas e fotografadas "in situ". Em seguida, com o auxílio de pinça e bisturi foram extraídas e armazenadas em frascos contendo álcool 70\% "overnight". As amostras foram desidratadas em concentrações crescentes de etanol (70-100\%) e diafanizadas em xilol, para posterior inclusão em parafina Histosec-MERCK (Tolosa et al. 2003). Foram realizados cortes dos blocos de parafina com $4 \mu \mathrm{m}$ de espessura, cortados em micrótomo rotativo de Parafina MRP09, os quais foram corados pelas técnicas de Hematoxilina-Eosina (HE). A fotodocumentação microscópica foi realizada com auxílio de fotomicroscópio Leica ICC50 HD. Todos os procedimentos foram realizados no Laboratório de Zoologia e Morfologia Animal, Unemat.

\section{RESULTADOS}

Neste estudo foi constatado que o exemplar de Glironia venusta apresentou cinco glândulas salivares: as glândulas mandibulares/cervicais, parótidas, sublinguais, labiais e zigomáticas (Fig.1).

As glândulas mandibulares, de coloração rosa-pálida, apresentaram-se como duas grandes estruturas alongadas, achatadas dorsoventralmente, constituídas por três lobos não-septados. Encontravam-se localizadas na porção anterior da região cervical, caudal ao músculo digástrico,

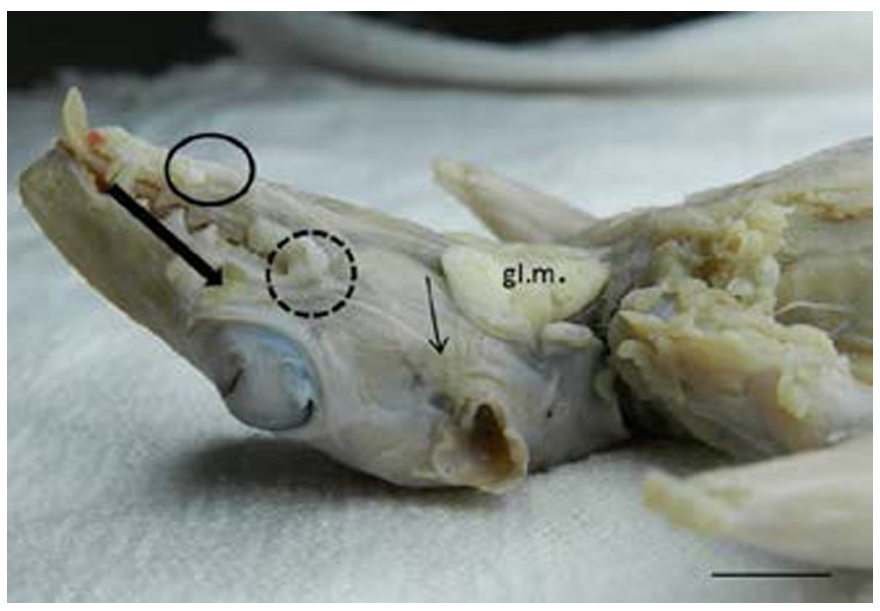

Fig.1. As glândulas salivares de Glironia venusta: glândula mandibular (gl.m.), glândula parótida (seta fina), glândula labial (círculo pontilhado), glândula zigomática (seta grossa), glândula sublingua7l (círculo). Barra $1 \mathrm{~cm}$. Fig.1. As glândulas salivares de Glironia venusta: glândula mandibular (gl.m.), glândula parótida (seta fina), glândula labial (círculo pontilhado), glândula zigomática (seta grossa), glândula sublingua7l (círculo). Barra $1 \mathrm{~cm}$. 


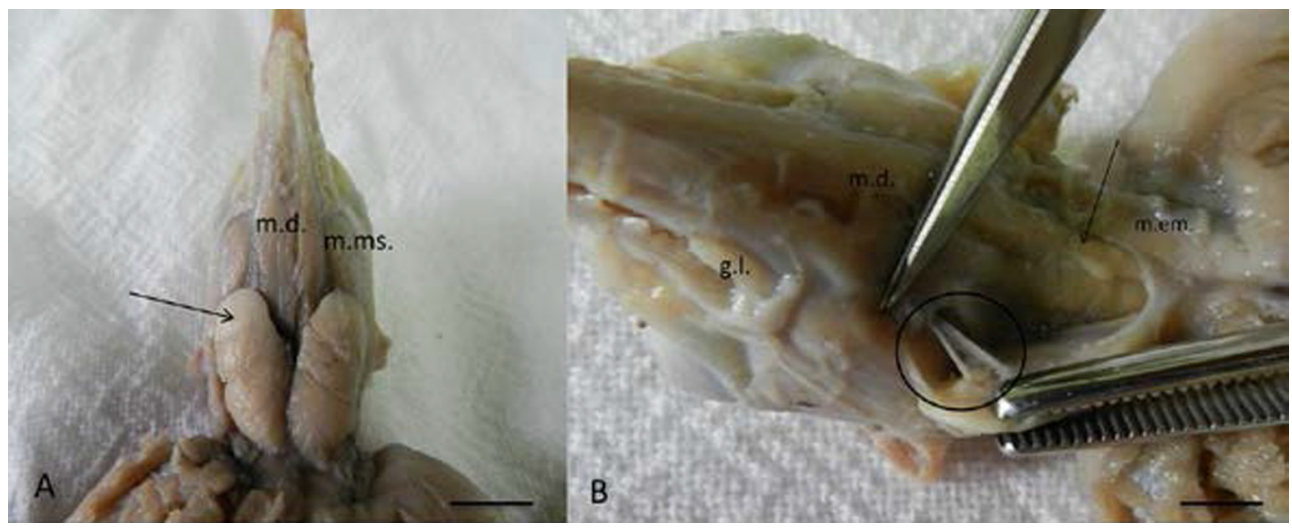

Fig.2. Visão ventral glândulas salivares mandibulares. (A) Gglândula mandibular (seta); músculo digástrico (m.d.), músculo masseter (m.ms.). (B) Glândula labial (g.l.), músculo digástrico (m.d.), músculo esternomastoide (m.em.), ducto mandibular (círculo). Barra $1 \mathrm{~cm}$.

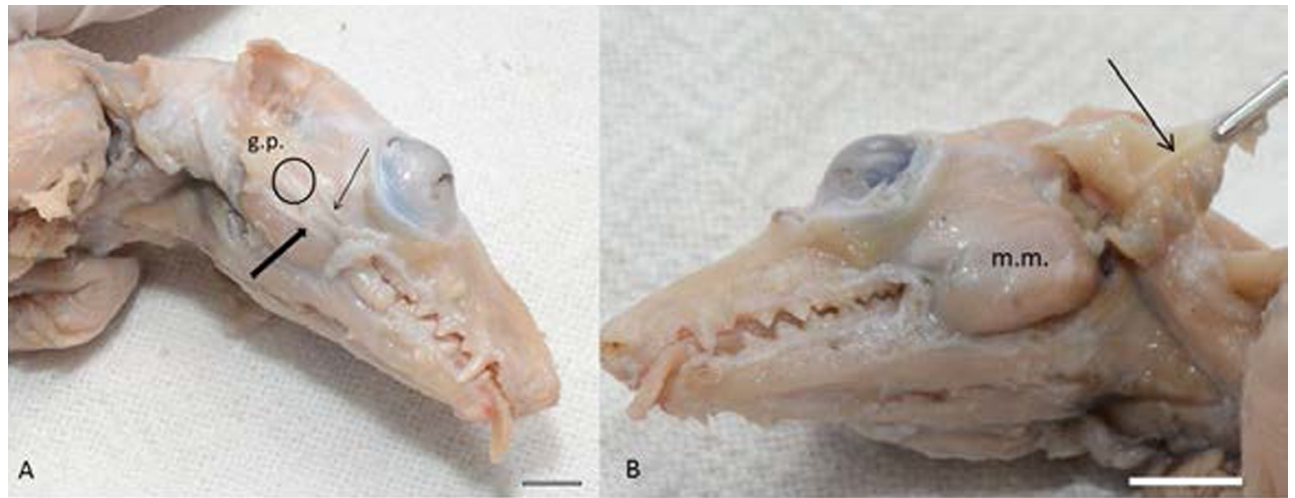

Fig.3. Glândula parótida. (A) Glândula parótida (g.p.), ducto parotídeo (círculo), nervo facial dorsal (seta fina), nervo facial ventral (seta grossa). (B) Músculo masseter (m.m.), ducto parotídeo (seta). Barra $1 \mathrm{~cm}$.

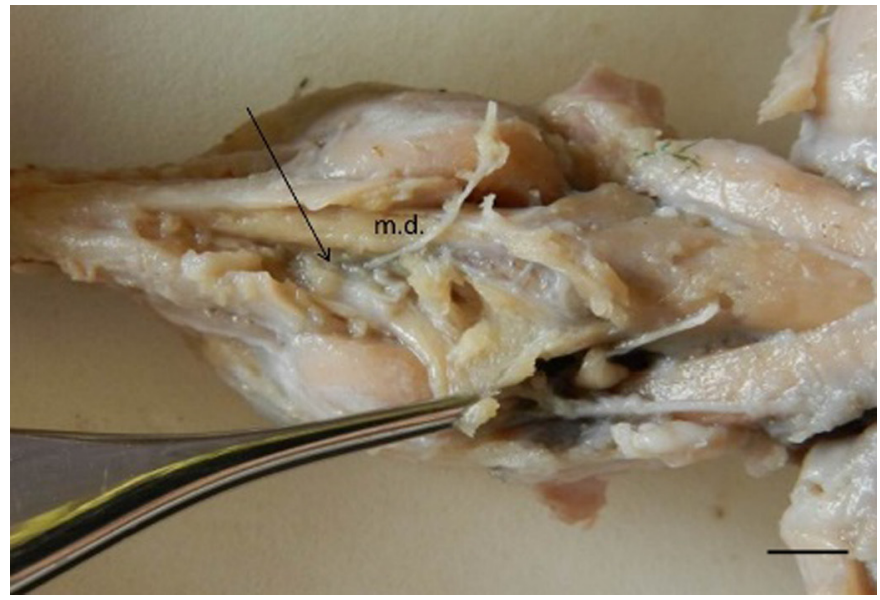

Fig.4. Visão ventral: glândula sublingual (seta), músculo digástrico (m.d.). Barra $1 \mathrm{~cm}$.

caudoventral ao músculo masseter e ventral aos músculos esternomastóideo e esternohióideo. Da superfície anterodorsal emergia o ducto mandibular que se estendia caudalmente ao músculo masseter e lateral ao músculo digástrico, até a superfície do assoalho da boca, próximo ao frênulo da língua (Fig.2).

As glândulas parótidas, de formato aproximadamente triangular e coloração parda esbranquiçada, encontravam-se na depressão do masseter, ventral à cartilagem auricu-

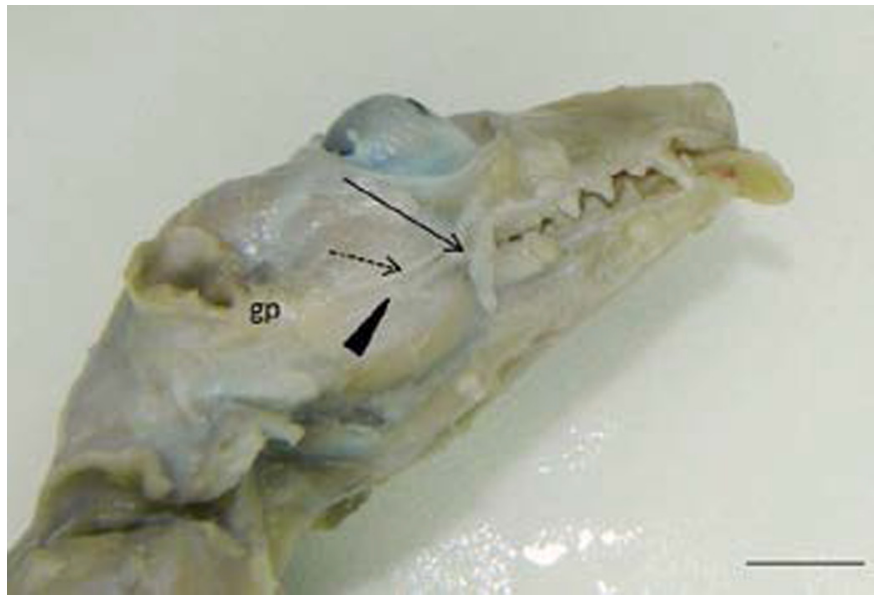

Fig.5. Visão lateral: glândula labial (seta), ducto parotídeo (cabeça de seta), nervo facial dorsal (seta pontilhada), glândula parótida (gp). Barra $1 \mathrm{~cm}$.

lar, dorsocaudal ao músculo masseter e cranial ao músculo esternomastóide. 0 ducto parotídeo se estendia em direção rostral cruzando superficialmente o músculo masseter, entre as ramificações dos nervos faciais dorsal e ventral, até a região ventral das glândulas labiais onde se aprofundava e se abria na porção média da cavidade bucal (Fig.3).

As sublinguais se mostraram como pequenas estruturas alongadas de coloração esbranquiçada, ventrais ao ramo da 
mandíbula, caudais ao digástrico, apresentando um ducto curto que emergia da sua extremidade cranial e se abria próximo à base da língua (Fig.4) .

Foram observadas na porção dorso posterior à comissura labial, dorsal ao músculo orbicular da boca, as glândulas labiais, que apresentaram formato de " $U$ ", seguindo a forma da comissura (Fig.5). Não foi possível observar o ducto desta glândula. Já as glândulas zigomáticas acompanhavam a forma da porção anterior do arco zigomático na margem infraorbital alongando-se suavemente sobre a maxila em forma de triângulo (Fig.6).

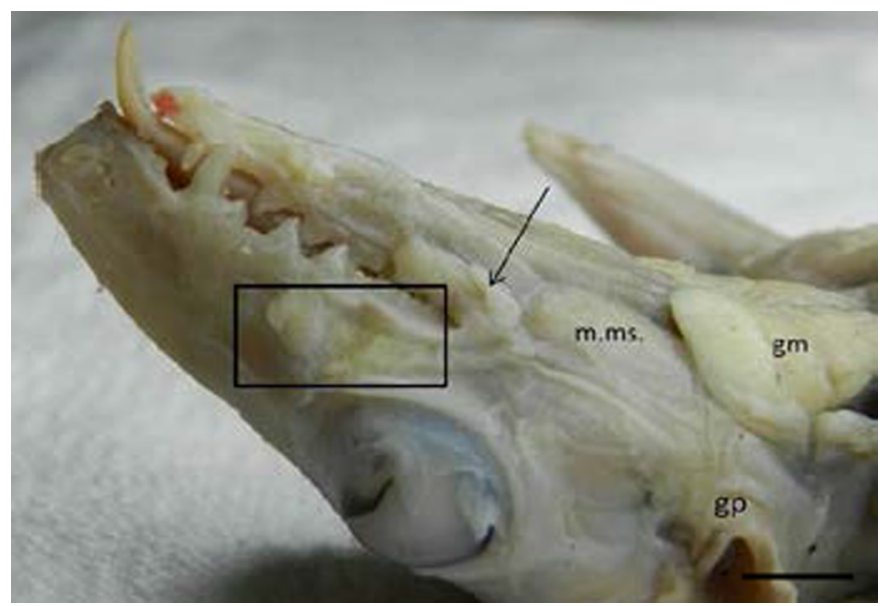

Fig.6. Vista lateral: glândula zigomática (retângulo), glândula labial (seta), músculo masseter (m.ms.), glândula parótida (gp), glândula mandibular (gm). Barra $1 \mathrm{~cm}$
Histologicamente as glândulas mandibulares, parótidas, sublinguais e labiais mostraram-se revestidas por uma cápsula constituída de tecido conjuntivo denso não-modelado, limitada externa e internamente por um epitélio simples pavimentoso. Este epitélio e o tecido conjuntivo adentravam a glândula formando septos, dividindo-a em lóbulos. Foram observados em algumas regiões dos septos agrupamentos de vasos sanguíneos, nervos e ductos interlobulares que formavam um conjunto semelhante a uma "tríade" ou "hilo" (Fig.7).

0 parênquima das glândulas mandibulares e sublinguais era composto por conjuntos de ácinos do tipo mucoso, constituídos por células de citoplasma claro, núcleo basal achatado e lúmen de formato irregular. Foram observados alguns raros ácinos serosos que apresentaram lúmen central arredondado, com células de formato triangular com núcleo apical arredondado (Fig.8).

As glândulas parótidas apresentaram um parênquima formado predominantemente por ácinos do tipo serosos de formato irregular, células arredondadas e núcleo redondo e central, com lúmen circular e central. 0 citoplasma se apresentou basófilo sem granulações. Formando o estroma da glândula foram observados, dispersos no tecido conjuntivo, uma série de feixes nervosos (Fig.9).

Ácinos do tipo misto foram observados constituindo o parênquima das glândulas labiais. Estes ácinos se apresentaram bem maiores que os mucosos e serosos, constituídos por uma lâmina basal formada por células serosas de formato achatado com núcleo redondo e central. Sua porção central mostrava uma série de camadas de células disformes, citoplasma claro e núcleo redondo formando esta

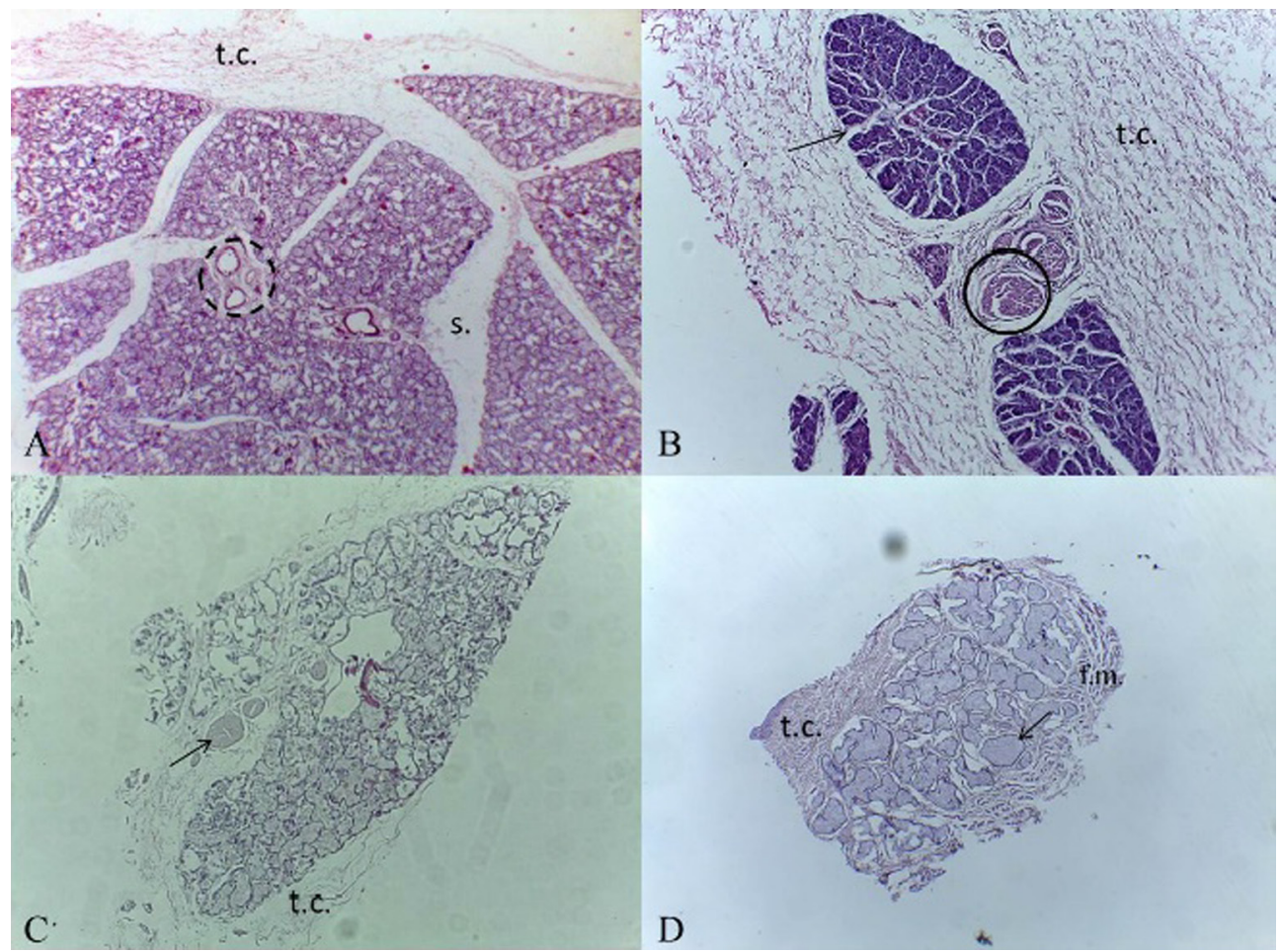

Fig.7. (A) Glândula mandibular: tecido conjuntivo denso não modelado (t.c.), ductos interlobulares (círculo), septo com tecido conjuntivo (s.). 10x. (B) Glândula parótida: feixe nervoso (círculo), septo com tecido conjuntivo (seta), tecido conjuntivo denso não-modelado (t.c.). 10x. (C) Glândula sublingual: feixe nervoso (seta), tecido conjuntivo denso não-modelado (t.c.). 4x. (D) Glândula labial: ácino misto (seta), feixe muscular (f.m.), tecido conjuntivo denso não-modelado (t.c.). 4x. 


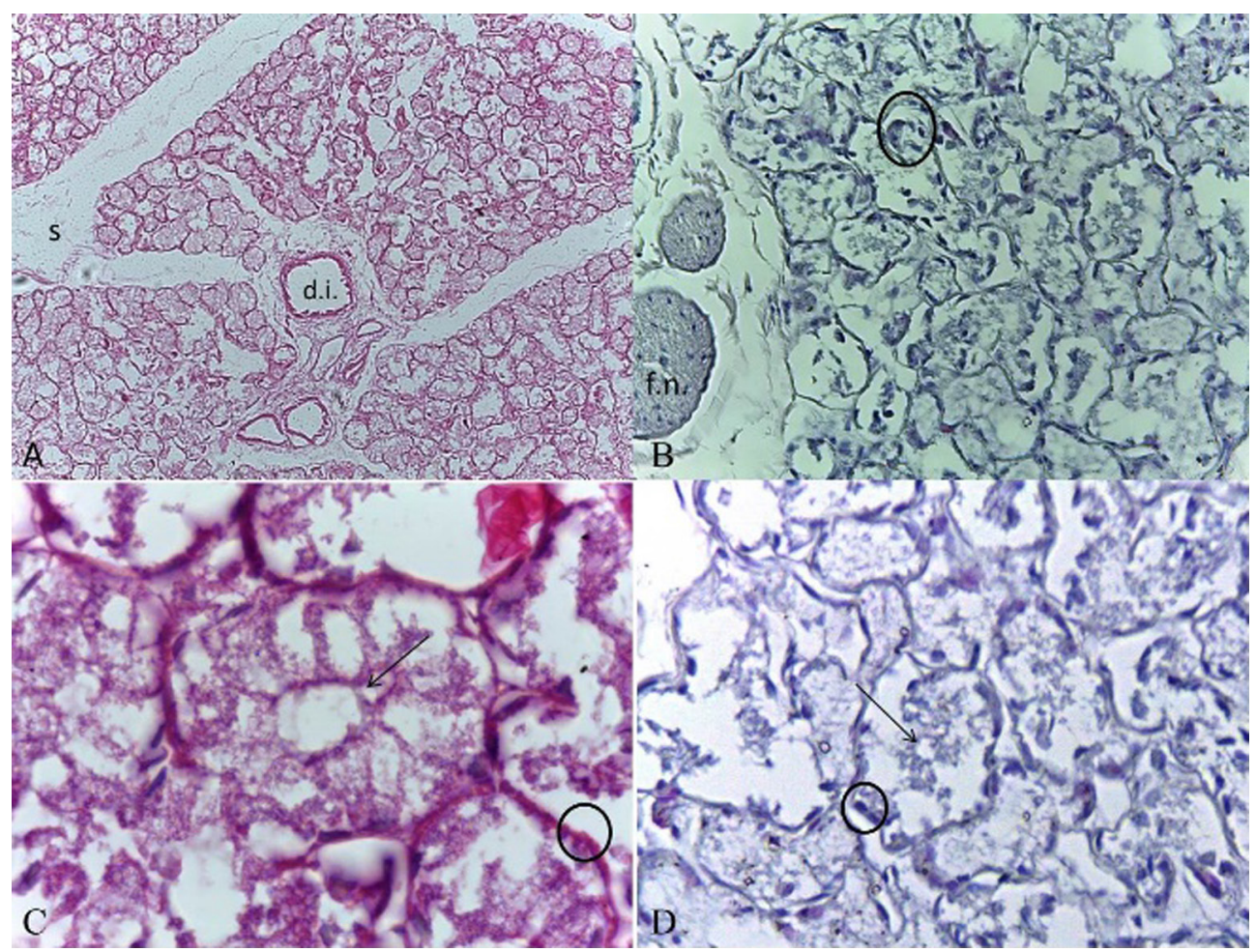

Fig.8. Glândulas mandibulares e sublinguais. (A) Glândula mandibular: septo com tecido conjuntivo (s), ducto interlobular (d.i.). 10x. (B) Glândula sublingual: feixe nervoso (f.n.), meia-lua serosa (círculo).40x. (C) Ácino mucoso da glândula mandibular e (D) da glândula sublingual. 100x: lúmen acinar (seta), núcleo basal (círculo). 40x.

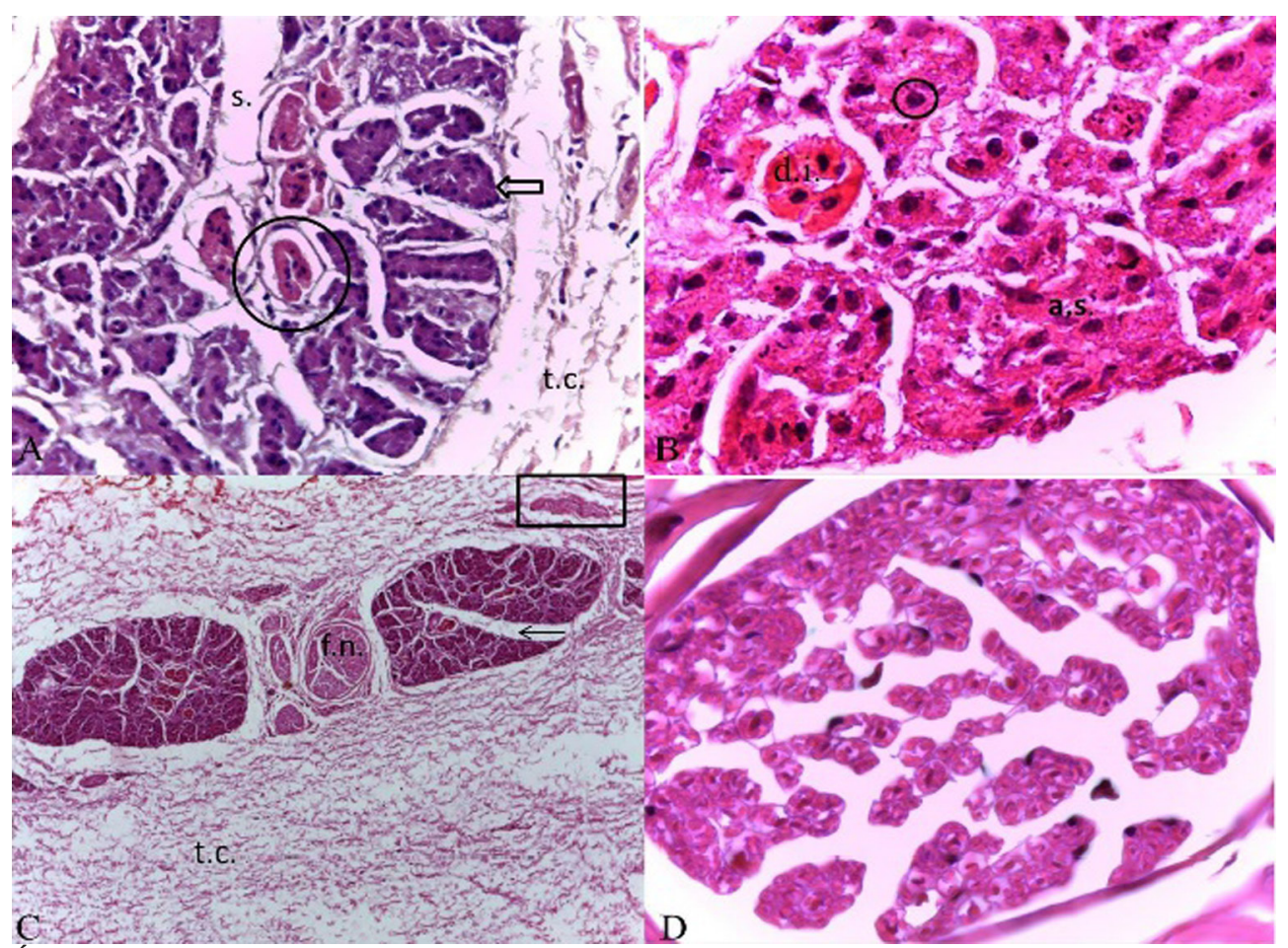

Fig.9. Parótida. (A) Ácino seroso (seta), septo (s.), ducto interlobular (círculo). 40x (B) Ducto intralobular (d.i.), núcleo central (círculo), ácino seroso (a.s.). 40x. (C) Tecido conjuntivo denso não-modelado (t.c.), feixe nervoso (f.n.), septo com tecido conjuntivo (seta), ducto parotídeo (retângulo).10x. (D) Feixe nervoso. 100x.

região. 0 lúmen destes ácinos não apresentou localização nem forma definida, mostrando por vezes lúmen de grande calibre, embora predominasse os de menor luz (Fig.10).
Constituindo a rede de drenagem das secreções acinares encontravam-se os ductos intercalares formando o canal excretor do ácino, os ductos intralobulares distribuin- 
do-se entre os lóbulos acinares, e os ductos interlobulares, dispersos nos septos de tecido conjuntivo (Fig.11).

Foram observados dois tipos de ductos interlobulares localizados nos septos de tecido conjuntivo. Estes apresentavam epitélio do tipo pseudo-estratificado com núcleos basais e apicais. Os ductos intercalares eram menores e se

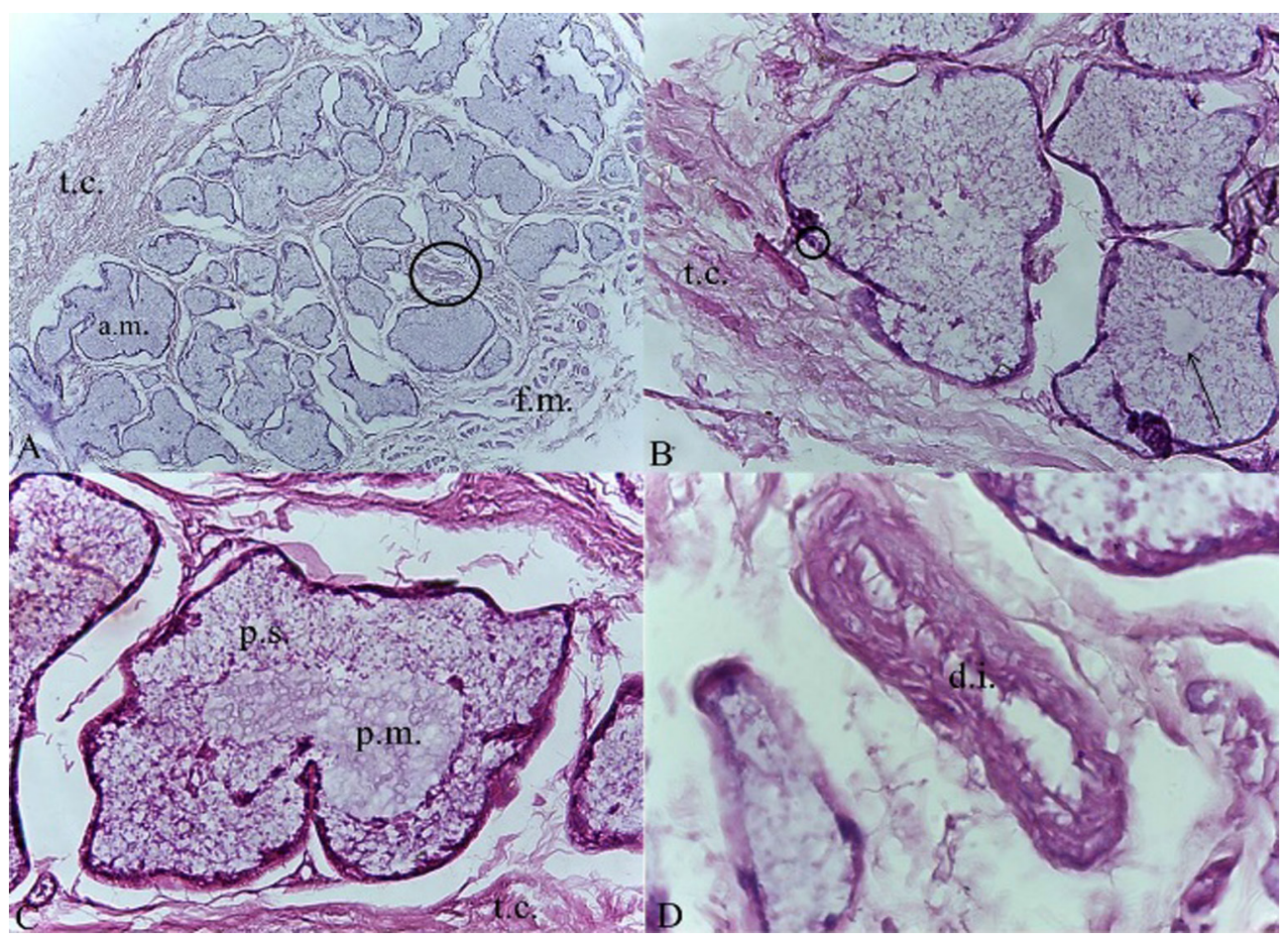

Fig.10. Glândula labial. (A) Feixe muscular (f.m.), ácino misto (a.m.), tecido conjuntivo denso não-modelado (t.c.), ducto intralobular (círculo). 10x. (B) Núcleo (ć́rculo), lúmen acinar (seta), tecido conjuntivo denso não-modelado (t.c.). 40x. (C) Porção serosa (p.s.), porção mucosa (p.m.), tecido conjuntivo denso não-modelado (t.c.).100x. (D) Ducto intralobular (d.i.). 100x.

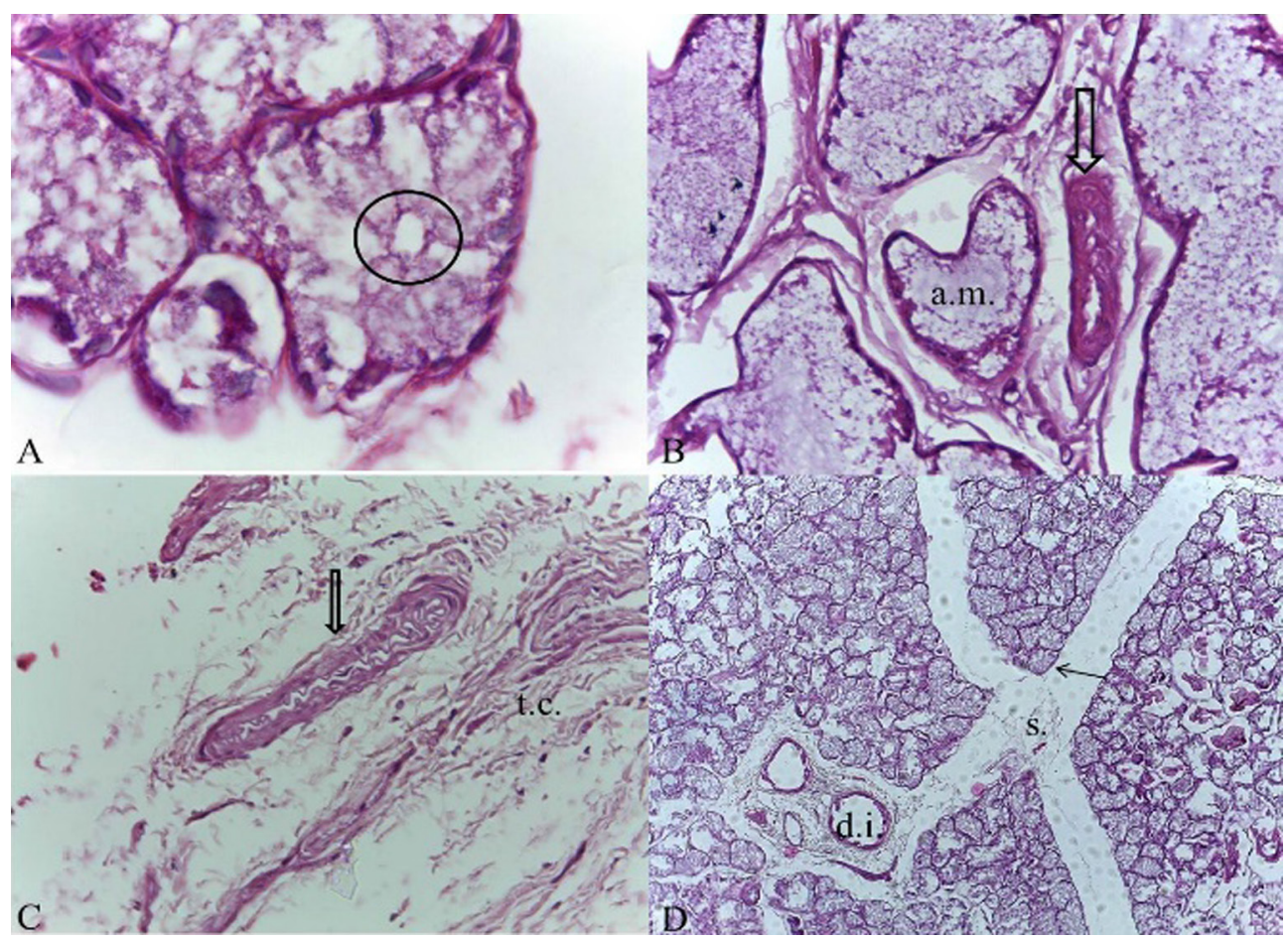

Fig,11. (A) Ducto intercalar da glândula mandibular (círculo).100x. (B) Ducto intralobular da glândula labial (seta), ácino misto (a.m.). 40x. (C) Ducto parotídeo (seta), tecido conjuntivo denso não-modelado (t.c.) 40x. (D) Ducto interlobular da glândula mandibular (d.i.), septo com tecido conjuntivo (s.), ácino mucoso (seta).10x. 


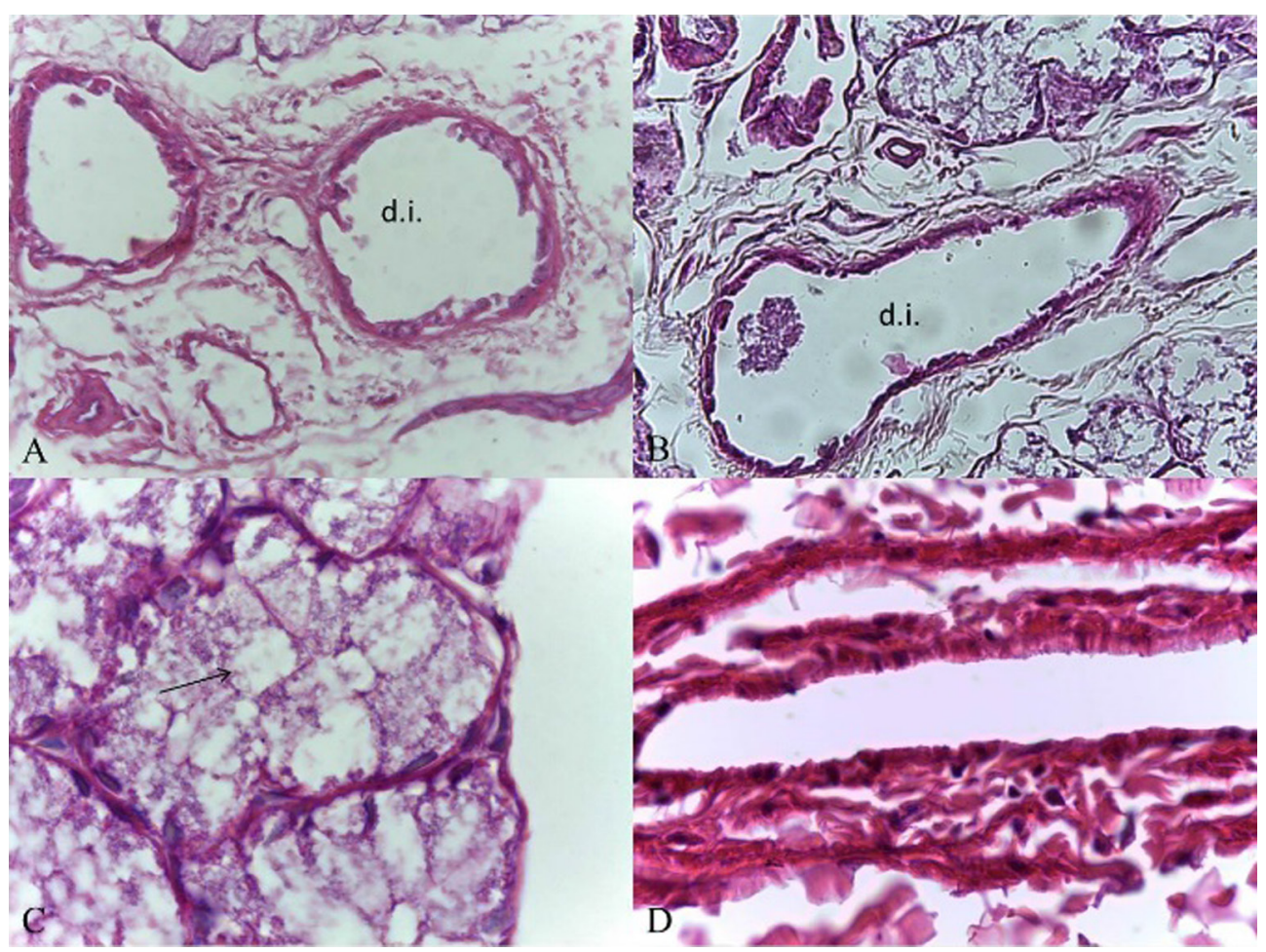

Fig.12. Os ductos. (A,B) Ductos interlobulares da glândula mandibular (d.i.).40x. (C) Ducto intercalar glândula mandibular (seta). (D) Ducto interlobular glândula parótida. 100x.

mostraram constituídos por um epitélio simples pavimentoso (Fig.12). As artérias e veias se mostraram com constituição usual. A histologia da glândula zigomática não foi realizada devido problemas de procedimentos histológicos.

\section{DISCUSSÃO}

Schimming (2009) classificou a glândula mandibular como glândula salivar cervical em Dasypus novemcinctus, provavelmente devido à sua localização. Não foi encontrada esta denominação em outros trabalhos, entretanto, a similaridade da localização em nossos achados torna possível esta denominação. A localização também é semelhante às descritas para Zaedyus pichiy (Estecondo et al. 2005), assim como sua constituição de três lobos (Codón et al 2003, Estecondo et al. 2005, Schimming 2009), em Nasua nasua (Santos et al. 2010), Procyon cancrivorus (Santos et. al. 2013), e Gracilinanus microtarsus (Lobo et al. 2014). Em Procyon cancrivorus foi descrita como de formato arredondado com seu ducto passando ao longo da face occiptomandibular do músculo digástrico e estiloglosso, emergindo na boca próximo ao frênulo da língua (Pereira 2012). Leirião-Riva (2005) descreveu em cães que este ducto está localizado lateralmente, entre o músculo masseter e a mandíbula, medial ao digástrico, estiloglosso e miloióideo, abrindo-se próximo ao frênulo da língua.

Foi descrito para glândula mandibular em Nasua nasua (Santos et al. 2012) e Procyon cancrivorus (Santos et al. 2013) uma cápsula de tecido conjuntivo denso não-modelado que formava septos e dividia a glândula em lóbulos, onde estavam presentes vasos sanguíneos, nervos e ductos interlobulares excretores, constituição similar aos nossos achados. Para glândula parótida foi descrita uma cápsula de tecido conjuntivo denso modelado em Dasypus novemcinctus (Schimming 2009) e para Cricetus cricetus (Khojasteh \& Delashoub 2012) um tecido conjuntivo denso, diferindo das nossas observações.

As glândulas mandibulares de Zaedyus pichyi apresentaram parênquima composto por ácinos mucosos com núcleos basais limitados por um citoplasma claro, preenchidos por meias-luas serosas. Os serosos se mostraram com células de forma triangular, núcleo central e citoplasma escuro. Estas características são semelhantes aos nossos achados, exceto pela localização dos núcleos dos ácinos serosos, que em G. venusta eram apicais. As estruturas acinares descritas para Rattus norvegicus e Cricetus auratus, (Munhoz 1967), Bolomys lasiurus (Cangussu et al. 2002),Dasypus novemcinctus (Schimming 2009) e Procyon cancrivorus (Santos et al. 2013) foram, predominantemente, do tipo mucoso, também tendo sido observados ácinos do tipo seromucosos ou mistos. Em camundongos foram encontrados por Pícoli et al. (2011) ácinos mucosos e serosos em quantidades relativas. Em nossos achados houve predominância de ácinos mucosos. Os componentes do parênquima como ductos, nervos e vasos sanguíneos foram semelhantes aos dos carnívoros domésticos (Dyce et. al. 2004) e silvestres (Santos et al. 2010).

A parótida em coelhos (Greco 2008), em Procyon cancrivorus e em Nasua nasua (Santos et al. 2012) estava localizada caudal ao ramo da mandíbula, desde a base do pavilhão auricular até o ângulo da mandíbula. Em sua extremidade ventral a glândula cobria lateralmente a glândula mandibular e, no seu terço dorsal, a origem do nervo facial, diferente do observado em $G$. venusta, que estava localizada na depressão do masseter, ventral à cartilagem auricular. 
Em relação a sua forma, difere do Nasua nasua que possui formato em "U", de Procyon cancrivorus, em "Y" (Santos et al. 2012), e em coelhos, que em alguns casos apresenta formato de pêra invertida ou de halteres (Greco 2008). No Nasua nasua e no Procyon cancrivorus, o ducto parotídeo se abre no vestíbulo oral, próximo da comissura labial e do quarto dente pré-molar superior, o que também foi encontrado em cães por Mendonça et al. (2004). A localização do ducto parotídeo pode variar entre as espécies e entre indivíduos de mesma espécie, como observado nos coelhos por Greco (2008), em que foram relatadas três diferentes localizações: dorsal, ventral e entre os ramos bucais dos nervos faciais.

Na glândula parótida foram observados ácinos do tipo serosos em Procyon cancrivorus e Nasua nasua (Santos et al. 2012) e em Zaedyus pichiy (Estecondo et al. 2005). Segundo Junqueira \& Carneiro (2004) ácinos serosos são característicos do homem, tendo sido descrito ácinos serosos para Cricetus cricetus (Khojasteh \& Delashoub 2012). Em carnívoros domésticos há predominância de ácinos mucosos (Dyce et al. 2010). Nas nossas análises foi constatada a presença de ácinos serosos como em outras espécies onívoras.

Não foi encontrada na literatura nenhuma denominação para glândula labial, entretanto, uma estrutura de forma e localização similar foi descrita em gatos, classificada de molar labial, com localização entre a mandíbula e o lábio (Okuda et al. 1996). Leirião-Riva (2005) informou que os ductos salivares labiais de cães, possuem aberturas distribuídas pela mucosa oral. Essas glândulas localizam-se entre os dentes molares e a mandíbula do cão, encontrando-se em pequena quantidade. Não foi possível visualizar o ducto excretor da glândula labial.

Referente à glândula labial, Barcelos e Andrade (2005) relatam que em humanos a maioria das glândulas salivares menores é constituída por ácinos com células mucosas e serosas, tendo por isso uma função glandular do tipo mista, corroborando com os achados em $G$. venusta

De acordo com Samuelson (2007) as glândulas sublinguais se caracterizam por apresentar uma distribuição de células mucosas ou serosas que variam consideravelmente dentro de cada glândula. Porções de lóbulos ou até mesmo o lóbulo inteiro podem ser exclusivamente serosos, entretanto, os adenômeros compostos por células mucosas raramente estão livres das células serosas. Ocasionalmente, estas apresentam formato de meia-lua e revestem externamente as células mucosas. Estas características também foram observadas em Zaedyus pichiy (Estecondo 2005) Segundo Kierszenbaum \& Tres (2012) tanto os ductos intercalares como os ductos estriados são poucos desenvolvidos e a glândula não é envolvida por uma cápsula bem definida, características também observadas em nosso espécime.

Getty (1986) e Dyce et al., (2004) descreveram que, em animais domésticos, a glândula zigomática está localizada na cavidade orbitária e seus limites são determinados pelo arco zigomático lateral e dorsalmente pela periórbita, ventralmente por gordura orbitária e pelo músculo pterigóide, e medialmente pela maxila. Possui quatro ductos que se abrem na mucosa lateral próxima ao último molar. $\mathrm{Na}$ espécie Procyon cancrivorus, a glândula zigomática era de formato arredondado e estava localizada na fossa pterigopalatina (Pereira 2012). Resultados esses que se assemelham aos encontrados em $G$. venusta.

\section{CONCLUSÕES}

As características das glândulas salivares observadas em $G$. venusta se assemelham à de outros mamíferos onívoros, entretanto apresentaram pequenas diferenças no que se refere à sua localização e forma.

Sobre a glândula labial, houve uma discordância sobre a sua denominação, pois em felinos está classificada como molar labial. Microscopicamente nossos achados e constituição se mostrou análoga a de outras espécies.

\section{REFERÊNCIAS}

Banks W.J. 1991. Histologia veterinária aplicada. $2^{\underline{a}}$ ed. Manole, São Paulo. 654p.

Barcelos K.S.A. \& Andrade L.E.C. 2005. Histopatologia e imunopatologia de glândulas salivares menores de pacientes com Síndrome de Sjögren (SSj). Revta Bras. Reumatol. 45(4):215-223.

Cangussu S.D., Vieira F.G. \& Rossoni R.B. 2002. Sexual dimorphism and seasonal variation in submandibular gland histology of Bolomys lasiurus (Rodentia, Muridae). J. Morphol. 254(3):320-327.

Codón S.M., Estecondo S. \& Casanave E.B. 2003. Histological study of the salivary glands in Dasypus hybridus (Mammalia, Dasypodidae). Int. J. Morphol. 21(3):199-204.

Dyce K.M., Sack W.O. \& Wensing C.J.G. 2004. Tratado de Anatomia Veterinária. $3^{\mathrm{a}}$ ed. Guanabara Koogan, Rio de Janeiro. 803p.

Dyce K.M., Sack W.O. \& Wensing C.J.G. 2010. Tratado de Anatomia Veterinária. $4^{a}$ ed. Guanabara Koogan, Rio de Janeiro. 878p.

Emmons L.H. \& Feer F. 1990. Neotropical Rainforest Mammals: a field guide. University of Chicago Press, Chicago. 396p.

Emmons L.H. \& Feer F. 1997. Neotropical Rainforest Mammals: a field guide. $2^{\text {nd }}$ ed. University of Chicago Press, Chicago. 307p.

Estecondo S., Codón S.M. \& Casanave E.B. 2005. Histological study of the salivary glands in Zaedyus pichiy (Mammalia, Xenarthra, Dasypodidae). Int. J. Morphol. 23(1):19-24.

Fonseca G.A.B., Herrmann G., Mittermeier Y.L.R., Rylands A.B. \& Patton J.L. 1996. Lista anotada dos mamíferos do Brasil. Occasional Papers in Conservation Biology, Boston, 3:1-38.

George L.L., Alver C.E.R. \& Castro R.R.L. 1998. Histologia Comparada. 2ª ed. Roca, São Paulo. 298p.

Getty R. 1986. Anatomia dos Animais Domésticos. Vol.2. 5a ed. Guanabara Koogan, Rio de Janeiro. 2000p.

Greco M.G., Bagetti-Filho H.J.S., Babinki M.A., Chagas M.A. \& Sampaio M.A.P. 2008. Anatomia da glândula parótida em coelhos. Revta Bras. Med. Vet. 30(2):129-131.

Junqueira L.C. \& Carneiro J. 2004. Histologia Básica. 10aㅡ ed. Guanabara Koogan, Rio de Janeiro. 488p.

Khojasteh S.M.B. \& Delashoub M. 2012. Microscopic anatomy of the parotid and submandibular salivary glands in European hamster (Cricetus cricetus L.). Int. Res. J. Appl. Basic Sci. 3:1544-1548.

Kierszenbaum A.L. \& Tres L.L. 2012. Histologia e Biologia Celular: uma introdução à patologia. $3^{\text {a }}$ ed. Elsevier, Rio de Janeiro. 720p.

Langguth A. \& Silva M. 1989. A new record of Glironia venusta from the Lower Amazon, Brazil. J. Mammal. 70:873-875.

Leirião-Riva F.P. 2005. Anatomia dos tecidos moles e glândulas salivares do sistema estomatogmático de cães e gatos: enfoque anátomo-cirúrgico. Dissertação de Mestrado em Anatomia dos Animais Domésticos e Silvestres, Faculdade de Medicina Veterinária e Zootecnia, Universidade de São Paulo, São Paulo, SP. 110p. 
Lobo L.M., Santos A.C., Rosa R.A., Ambrósio C.E., Briani D.C., Costa G.M., Carvalho A.F. \& Mançanares C.A.F. 2014. Estudo macroscópico do aparelho digestório de Gracilinanus microtarsus Wagner, 1842 (Mammalia: Didelphidae). Biotemas 27:109-120.

Marshall L.G. 1978. Glironia venusta. Mammalian Species 107:1-3.

Mendonça C.S., Silva F.O.C., Cunha G.N. \& Coelho H.E. 2004. Topografia da papila parotidea em cães sem raça definida. Biotemas 17(1):217-224.

Munhoz C.O.G. 1967. Estudo histoquímico comparativo (proteínas e carboidratos) das glândulas salivares maiores de três ordens de mamíferos (artiodáctilos, carnívoros e roedores). Tese de Doutorado, Faculdade de Odontologia de Piracicaba, Universidade de Campinas, Piracicaba, SP. 118p.

Nowak R.M. 1999. Walker's Mammals of the World. Vol.1. 6th ed. Johns Hopkins University Press, Baltimore.

Okuda A., Inouc E. \& Asari M. 1996. The membranous bulge lingual to the mandibular molar tooth of cat constains a small salivary gand. J. Vet. Dentistry 13(2):61-63.

Pereira K.F. 2012. Procyon cancrivorus (Mão Pelada): aspectos morfológicos das glândulas salivares e distribuição do nervo isquiático. Tese de Doutorado, Escola de Veterinária e Zootecnia, Universidade Federal de Goiás, Goiânia. 43p.

Pícoli L.C., Dias F.J., Issa J.P., Ogawa K., Ciena A., Iyomasa M.M., Lopes R.A. \& Watanabe I.S. 2011. Ultrastructure of submandibular salivary glands of mouse: TEM and HRSEM observations. Microsc. Res. Tech. 74(6):11541160.

Samuelson D.A. 2007. Textbook of Veterinary Histology. Saunders-Elsevier, Philadelphia. 546p.
Santos A.C., Bertassoli B.M., Oliveira V. C., Carvalho A.F., Rosa R.A. \& Mançanares C.A.F. 2010a. Morfologia dos músculos do ombro, braço e antebraço do quati (Nasua nasua, Linnaeus, 1758). Biotemas, Florianópolis, 23(3):167-173.

Santos A.C., Bertassoli B.M., Oliveira V.C., Rosa R.A., Carvalho A.F. \& Mançanares C.A.F. 2010b. Caracterização morfológica das glândulas salivares mandibulares dos quatis (Nasua nasua Linnaeus, 1758). Revta Fac. Zootec. Vet. Agron., Uruguaiana, 17(2):276-286.

Santos A.C., Bertassoli B.M., Oliveira F.D., Oliveira D.M., Oliveira V.C., Vasconcelos B.G., Carvalho A.F., Mançanares C.A.F. \& Neto A.C.A. 2012. Estrutura macro e microscópica das glândulas salivares parótidas em duas espécies de procionídeos: mão pelada (Procyon cancrivorus G. Cuvier, 1978) e quati (Nasua nasua Linnaeus, 1766). Biotemas 25(1):93-101.

Santos A.C., Oliveira V.C., Viana D.C., Lobo L.M., Ambrósio C.E., Assis-Neto A.C., Carvalho A.F. \& Mançanares C.A.F. 2013. Análise microscópica e ultraestrutural das glândulas salivares mandibulares de Procyon cancrivorus. Pesq. Vet. Bras. 33(Supl.1):39-44.

Schimming B.C. 2009. Morphological study of the cervical salivary glands in the nine-banded armadillo. Int. J. Morphol. 27(3):737-742.

Tarifa T. \& Anderson S. 1997. Two additional records of Glironia venusta Thomas, 1912 (Marsupialia, Didelphidae) for Bolívia. Mammalia 61: 111-113.

Tolosa E.M.C., Rodrigues C.J., Behmer O. \& Freitas Neto A.G. 2003. Manual de Técnicas para Histologia Normal e Patológica. $2^{a}$ ed. Manole, São Paulo. 331p.

Vieira M.B.M., Pereira R.A., Santos J.R.N.B. \& Pinto R.V. 2001. Ressecção subcapsular da glândula submandibular. Revta Bras., Otorrinolaringol. 67(6):825-828. 